\title{
Composition and structure of microbial communities associated with different domestic sewage outfalls
}

Z.H. Wang', J.Q. Yang ${ }^{2}$, D.J. Zhang ${ }^{1}$, J. Zhou ${ }^{1}$, C.D. Zhang ${ }^{1}$, X.R. Su ${ }^{1}$ and T.W. $\mathbf{L i}^{3}$

${ }^{1}$ School of Marine Science, Ningbo University, Ningbo, Zhejiang Province, China

${ }^{2}$ North China Sea Branch of The State Oceanic Administration, Qingdao, Shandong Province, China

${ }^{3}$ Ningbo City College of Vocational Technology, Ningbo,

Zhejiang Province, China

Corresponding authors: X.R. Su

E-mail: suxiurong@nbu.edu.cn

Genet. Mol. Res. 13 (3): 7542-7552 (2014)

Received July 29, 2013

Accepted March 15, 2014

Published September 12, 2014

DOI http://dx.doi.org/10.4238/2014.September.12.21

\begin{abstract}
The diversity of microbiota in waste waters has not been thoroughly examined, despite the potential impact of microbes on effluent quality. Wastewater microbial communities harbor pathogenic bacteria, viruses, and parasites. To study microbial communities in domestic sewage outfalls, 454 pyrosequencing technology was used to investigate the composition of microbial communities associated with municipal wastewater during different seasons sampled over the course of one year. A total of 195,103 16S rRNA gene sequences were obtained from 20 samples. The R software was used to calculate the number of indices describing the alpha diversity associated with each bacterial assemblage. In this study, the $\alpha$-diversity index $\left(\mathrm{H}^{\prime}, \mathrm{D}, \mathrm{J}\right)$, in which higher numbers represent more diversity, was found to change with seasonal cycle. The diversity of bacterial assemblages was high
\end{abstract}


in all samples, indicating that species diversity was also very high. The taxonomic composition of the assemblages varied considerably among samples, with some dominated by Proteobacteria, while others were dominated by Bacteroidetes or Firmicutes. In 2 samples, the relative prevalence of Proteobacteria exceeded $90 \%$. $\alpha$-Proteobacteria, $\beta$-proteobacteria, and $\gamma$-proteobacteria represented $90 \%$ or more of all Proteobacteria. The present characterization of wastewater from five sewage outfalls indicated the presence of some pathogenic bacteria. The $\gamma$-Proteobacteria in sewage wastefalls identified in this study included Enterobacteriaceae, Vibrionaceae, Pseudomonadaceae, Salmonella, Yersinia, Vibrio, and Pseudomonas aeruginosa.

Key words: Sewage; Bacterial diversity; 454 Pyrosequencing; Metagenomics

\section{INTRODUCTION}

Domestic sewage contains high concentrations of pollutants, including suspended solids, organics, and nutrients, which can cause a large amount of damage to marine environments (Teodoro et al., 2010). Bacteria are the most abundant and diverse group of organisms living in wastewater (Despland et al., 2012; Yu et al., 2012). The microbial diversity in sewage is very high, yet even a basic understanding of how this diversity is distributed ecologically is lacking. A better understanding of sewage microbial communities will not only provide an important framework for the design and operation of stable wastewater treatment systems, but also will enrich the study of microbial ecology.

Culture-based methods are biased in their evaluation of microbial diversity, are timeconsuming, and provide information on only approximately $1 \%$ of bacteria that are amenable to cultivation (Nocker et al., 2007). As with cult uring, the primary drawbacks of molecular methods include both labor and financial costs. Recently, DNA sequencing has been revolutionized by the introduction of massively parallel sequencing systems, such as 454 pyrosequencing analysis (Margulies et al., 2005; Cristea-Fernstrom et al., 2007; Huse et al., 2007; Liu et al., 2007; Roesch et al., 2007; Sundquist et al., 2007). Pyrosequencing techniques are high-throughput analytical tools that are capable of generating large numbers of DNA reads through a massively parallel sequencing-by-synthesis approach (Margulies et al., 2005). This technology is extensively used in the analysis of microbial communities in various environmental samples (Ye et al., 2011), including the marine water column (Qian et al., 2011), terrestrial soils (Roesch et al., 2007), human distal intestinal content (Claesson et al., 2009), and wastewater treatment plant influent (McLellan et al., 2010).

The diversity of microbiota of wastewaters has not been thoroughly examined, despite the potential role that microbes have on the quality of effluent. This is particularly true in developing countries, where wastewater from residences and factories flow through a series of drains that ultimately lead to the sea. These drains, known as sewage sea outfalls, exist in various sizes and shapes (State Oceanic Administration of the People's Republic of China). In recent years, increased economic productivity has impacted sewage outfalls, notably by decreasing the water quality of nearby coastal waters (Li et al., 2011; Wang et al., 2011). Ningbo 
is located in the middle coastline of Mainland China. The primary sea waters near Ningbo include the south coast of Hanzhou Bay, the mouth of the Yong River, the Xiangshan port, Sanmen Bay, and the adjacent sea areas of Beilun to Daxie. Environmental monitoring has indicated that wastewater overflow is common in the sewage draining outfalls in this area (Ningbo City Ocean and Fishery Bureau, China). Heavy pollution poses a profound threat to the ecology of the macro and microbial communities in coastal waters. Xiangshan port, located in the northern coastal area of Zhejiang, is a long, narrow, and semi-enclosed bay near the northeast and further inland to the southwest. The bay is spotted with numerous types of wastewater outlets. Because of geographical reasons, little exchange occurs between this bay and the external seawater. As a result, the bay exhibits a unique microbial diversity that is distinct from that found in open seawater (Kent et al., 2001; Li et al., 2006; Schnetzer et al., 2011). Most studies to date have focused on wastewater treatment systems themselves, while reports of the bacterial diversity associated with domestic sewage are rare. In this study, we investigated the microbial diversity associated with sewage outfalls in Xiangshan port in samples collected in different months using high-throughput pyrosequencing technology. Each sample underwent two types of treatment processes operated in parallel. This allowed comparison of community with respect to i) each type of treatment system, ii) between samples, and iii) between samples collected over an annual cycle.

\section{MATERIAL AND METHODS}

\section{Sample collection}

All samples from the 5 sewage outlets were collected in Ningbo, China in 2011. Among them, S1 was located in Xiangshan County, samples S2 and S3 were located in Ninghai County, S4 was located in Fenghua County, and S5 was located in Beilun district. Details regarding these outlets are shown in Figure 1, and all the 5 sewage outlets were near Xiangshan port. According to a study by the Ningbo City Ocean and Fishery Bureau and State Oceanic Administration of the People's Republic of China, the 5 sewage outlets have been subsumed into domestic sewage outfalls.

Untreated wastewater samples were collected in clean, pre-sterilized 5-L containers. Samples were collected during different seasons: winter (March), spring (May), summer (August), and autumn (October). For each of the 5 sites, samples collected in March were named Mar1, Mar2, Mar3, Mar4, and Mar5, respectively; samples collected in May were named May1, May2, May3, May4, and May5, respectively; samples collected in August were named Aug1, Aug2, Aug3, Aug4, and Aug5, respectively; and samples collected in October were named Oct1, Oct2, Oct3, Oct4, and Oct5, respectively. The wastewater samples collected were brought to the laboratory and filtered immediately. Seawater samples were filtered through $0.2-\mu \mathrm{m}$ polycarbonate filters (Poretics Products; Livermore, CA, USA). Filters for DNA extraction were stored at $-80^{\circ} \mathrm{C}$ until processing.

\section{DNA extraction and pyrosequencing}

Total genomic DNA was extracted from the filters using the Fast DNA SPIN kit for Water (Omega Bio-Tek; Norcross, GA, USA), according to manufacturer instructions. To 
ensure sample quality, DNA extracts must have had an absorbance ratio at 260 to $280 \mathrm{~nm}$ and at 260 to $230 \mathrm{~nm}$ of 1.80-2.00 and $>1.70$, respectively. Fragments of the bacterial $16 \mathrm{~S}$ rRNA gene were amplified by polymerase chain reaction (PCR) using the following primers: forward primer 5'-CCATCTCATCCCTGCGTGTCTCCGACTCAG and reverse primer 5'-CCTATCCCCTGTGTGCCTTGGCAGTCTCAG (Yang et al., 2012). PCR reactions were performed in a $20-\mu \mathrm{L}$ volume containing $2 \mu \mathrm{L} 10 \mathrm{X}$ Ex Taq Buffer $\left(\mathrm{Mg}^{2+}\right.$-free $), 2 \mathrm{mM} \mathrm{MgCl}$, $0.2 \mathrm{mM}$ dNTP, $0.4 \mu \mathrm{M}$ of each forward and reverse primers, $0.2 \mathrm{U}$ TaKaRa Ex Taq, and 50$100 \mathrm{ng}$ DNA template (TaKaRa; Shiga, Japan). Amplification was carried out with the following PCR program: $94^{\circ} \mathrm{C}$ for $5 \mathrm{~min}, 94^{\circ} \mathrm{C}$ for $1 \mathrm{~min}, 55^{\circ} \mathrm{C}$ for $1 \mathrm{~min}$, and $72^{\circ} \mathrm{C}$ for $1 \mathrm{~min}$ for 35 cycles. A final 10-min extension step at $72^{\circ} \mathrm{C}$ was also performed. PCR products were stored at $4{ }^{\circ} \mathrm{C}$. PCR products were confirmed using $2 \%(\mathrm{w} / \mathrm{v})$ agarose gel. The DNA band with the correct size was excised and purified using a PCR clean-up system. Equal amounts of purified PCR products were pooled for subsequent 454 pyrosequencing.

In order to determine the composition of the bacterial communities, purified PCR products were subjected to shotgun pyrosequencing using 454 GS Junior and Titanium chemistry (454 Life Sciences-OE Biotech Company; Shanghai, China). 454 Pyrosequencing was carried out on the Titanium platform (Roche/454 Life Sciences; Basel, Switzerland). Emulsion PCR was set up according to the manufacturer protocol (McKenna et al., 2008). Each sample was tested three times.

\section{Sequence analysis}

Raw sequence data was sorted based on sample-specific barcode tags. Primers and barcodes were trimmed from sorted sequences. Raw sequences were processed through the Ribosomal Database Project II (RHD-II) pyrosequencing pipeline (Cole et al., 2009). First, ambiguous and short sequences less than $150 \mathrm{bp}$ in length were removed. Second, qualified sequences were clustered into operational taxonomic units (OTUs) defined by a $3 \%$ distance level using complete-linkage clustering. Third, these sequences were assigned to phyla using the RDP-II classifier at a 50\% confidence threshold (Wang et al., 2007). The sequences were clustered based on the similarity threshold of $97 \%$ sequence identities.

The R (v .2.14.2, http://www.r-project.org/) software was used to calculate a number of indices describing the alpha diversity associated with each bacterial assemblage, including the Shannon-Wiener index (H'), the Simpson's diversity index (D), and Simpson's evenness index $(\mathrm{J})$. Heat maps were drawn by hierarchal clustering performed in $\mathrm{R}$ (g plots).

\section{RESULTS AND DISCUSSION}

As shown in marine, soil, and human gut samples, massively parallel pyrosequencing permits the exploration of microbial diversity in complex communities in unprecedented depth (Huber et al., 2007; Acosta-Martínez et al., 2008; Dethlefsen et al., 2008; Bissett et al., 2011). Pyrosequencing has afforded researchers the ability to detect the 'rare biosphere' to a greater extent than possible using traditional clone library approaches (Fabrice and Didier, 2009; Ye et al., 2011). This technology has contributed to the discovery of novel sequences that potentially represent new species (Suau et al., 1999; Im et al., 2012). In this study, we used pyrosequencing to characterize the composition and structure of bacterial populations in 
5 geographically distinct sewage outfall samples, and identified shifts in the composition of these assemblages over a period of a year. A total of 195,103 sequence tags were obtained for the 20 samples analyzed in this study (Table 1). Cluster analysis was used to compare community composition and to investigate the common taxonomic classes that lead to the overall patterns in clustering. The samples were analyzed based on the composition of the microbial community and the relative number bacteria at the phylum level. The bacterial community associated with Oct5, sampled in October, was significantly different from that of other samples acquired from other outlets (Figure 1). In October, Firmicutes was the dominant class. Other samples, particularly Mar4, May2, May3, Oct4, May4, Aug5, and Oct2, showed considerable similarity and were ranked into one category. In addition, the bacterial communities associated with Mar5 and Oct3 showed the most similarity.

Table 1. Sample information, comparison of phylotype coverage and diversity estimation of the 16S rRNA gene libraries obtained from the pyrosequencing analysis.

\begin{tabular}{|c|c|c|c|c|}
\hline Sample name & Good reads ${ }^{\mathrm{a}}$ & $\mathrm{H}^{\prime}$ & $\mathrm{D}$ & $\mathrm{J}$ \\
\hline Mar1 & 14083 & 3.72 & 0.81 & 0.76 \\
\hline May1 & 12996 & 4.51 & 0.91 & 0.84 \\
\hline Aug1 & 3925 & 4.18 & 0.87 & 0.81 \\
\hline Oct1 & 3757 & 5.06 & 0.95 & 0.88 \\
\hline Mar2 & 10077 & 3.91 & 0.83 & 0.92 \\
\hline May2 & 13878 & 3.92 & 0.83 & 0.81 \\
\hline Aug2 & 5432 & 4.31 & 0.89 & 0.83 \\
\hline Oct2 & 8672 & 4.26 & 0.88 & 0.81 \\
\hline Mar3 & 12858 & 2.52 & 0.72 & 0.57 \\
\hline May3 & 13715 & 4.67 & 0.93 & 0.92 \\
\hline Aug3 & 5413 & 4.11 & 0.87 & 0.78 \\
\hline Oct3 & 8763 & 4.60 & 0.92 & 0.85 \\
\hline Mar4 & 11763 & 2.94 & 0.77 & 0.62 \\
\hline May4 & 15446 & 3.05 & 0.79 & 0.61 \\
\hline Aug4 & 6973 & 4.04 & 0.87 & 0.71 \\
\hline Oct4 & 6650 & 4.17 & 0.88 & 0.75 \\
\hline Mar5 & 12391 & 3.86 & 0.81 & 0.86 \\
\hline May5 & 13208 & 4.17 & 0.87 & 0.83 \\
\hline Aug5 & 5560 & 5.09 & 0.95 & 0.94 \\
\hline Oct5 & 9543 & 4.55 & 0.92 & 0.83 \\
\hline
\end{tabular}

a Reads exceeding 150 bp were considered to be good reads. $\mathrm{H}^{\prime}$ = Shannon-Wiener index, in which higher numbers indicate more diversity. $\mathrm{D}=$ Simpson's Diversity index, in which higher numbers indicate more diversity. $\mathrm{J}=$ Simpson's Evenness index, in which high numbers indicate more evenness.

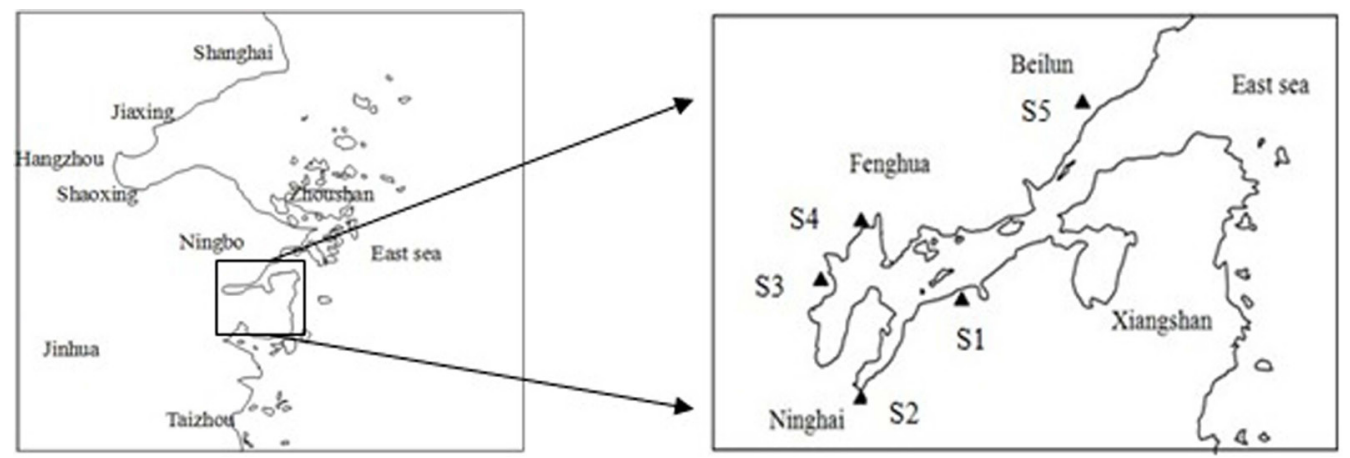

Figure 1. Map of sampling site. 


\section{Structure of bacterial communities in different samples}

The composition of bacterial 16S rRNA genes associated with various sewage samples differed at the phylum level (Figure 2). In most samples, the predominant phylum was Proteobacteria, while the next most common phyla included Bacteroidetes, Acidobacteria, Cyanobacteria, and Firmicutes, in this order. In 2 samples, the relative prevalence of Proteobacteria exceeded 90\% (May2, 90.2\%; May3, 91.7\%). Surprisingly, the percentage of Proteobacteria was only $3.8 \%$ in sample Oct5; in this sample, Firmicutes was the predominant phylum. In Mar3, sequences associated with Firmicutes represented 33\% of the total sample, while the relative abundance of other taxonomic classes was lower than $10 \%$. For the May 1 sample, the relative prevalence of Verrucomicrobia was $12 \%$, which was higher than that found in the other samples.

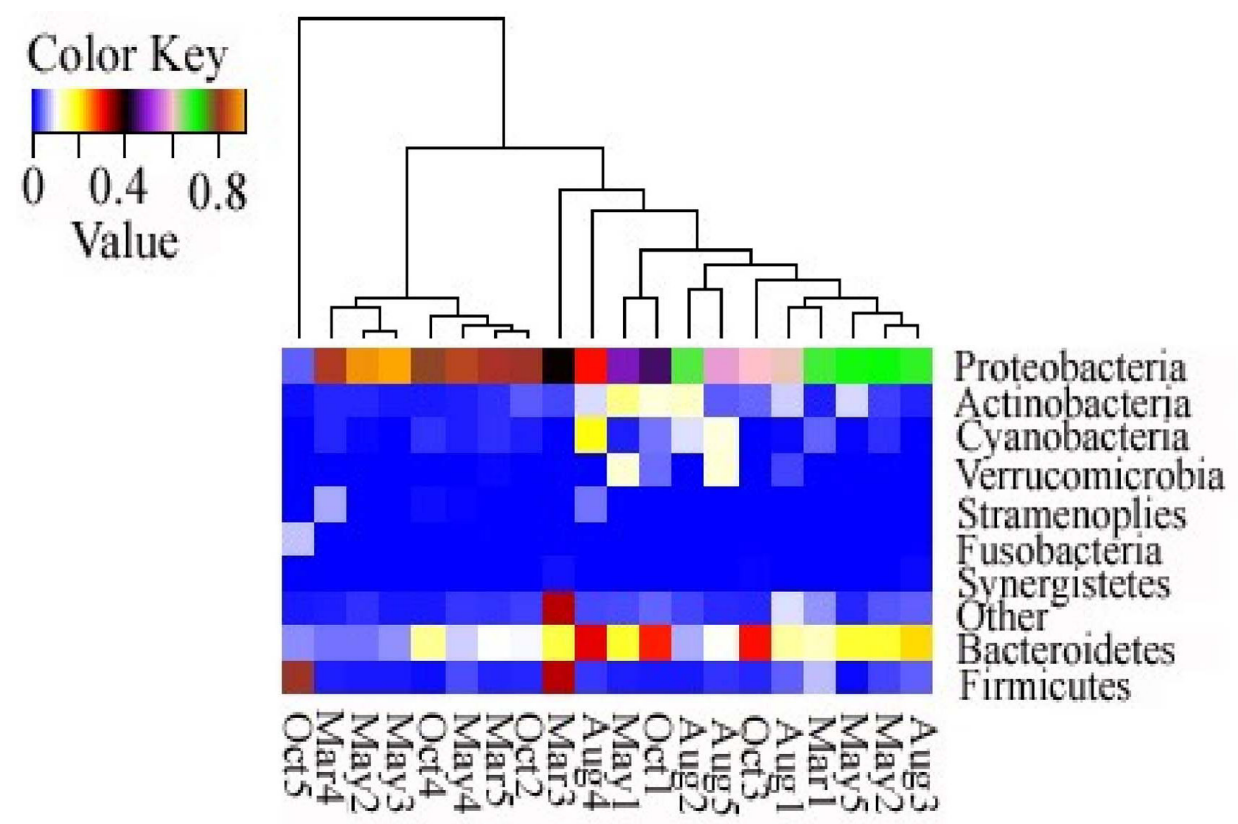

Figure 2. Clustering of sequences, defined at the phylum level, for different samples. The prevalence of microorganisms among five sewage outfalls from different month. Raw sequences were processed through the Ribosomal Database Project II (RHD-II) pyrosequencing pipeline, and the sequences were clustered based on the similarities of $97 \%$ sequence identities. The linkages of the dendrogram do not show phylogenetic relationship of the bacterial classes, but it is based on relative abundance of taxonomic profiles. The heat map color represents the relative percentage of the microbial descriptions within each sample, with the legend indicated at the upper left corner. Different colors represent relative percentage. Blue represents lower content and orange represents higher content.

The structures of microbial communities in different samples acquired during the same month were investigated in this study (Figure 2). As shown in Figure 3A, the relative abundance of Proteobacteria did not change significantly during the sampling period in sample $\mathrm{S} 1$, but the relative abundance of Bacteroidetes did change. In October, the percentage of this 
phylum was twice that observed in March. While the abundance of sequences affiliated with Proteobacteria did not change, the composition of these sequences was distinct. For example, in March, sequences affiliated with $\gamma$-proteobacteria were dominant, where as in other months, $\beta$-proteobacteria dominated these communities. $\gamma$-Proteobacteria consists of Enterobacteriaceae, Vibrionaceae, and Pseudomonadaceae. Some pathogenic bacteria are affiliated with $\gamma$-proteobacteria, including genera such as Salmonella, Yersinia, Vibrio, and Pseudomonas.

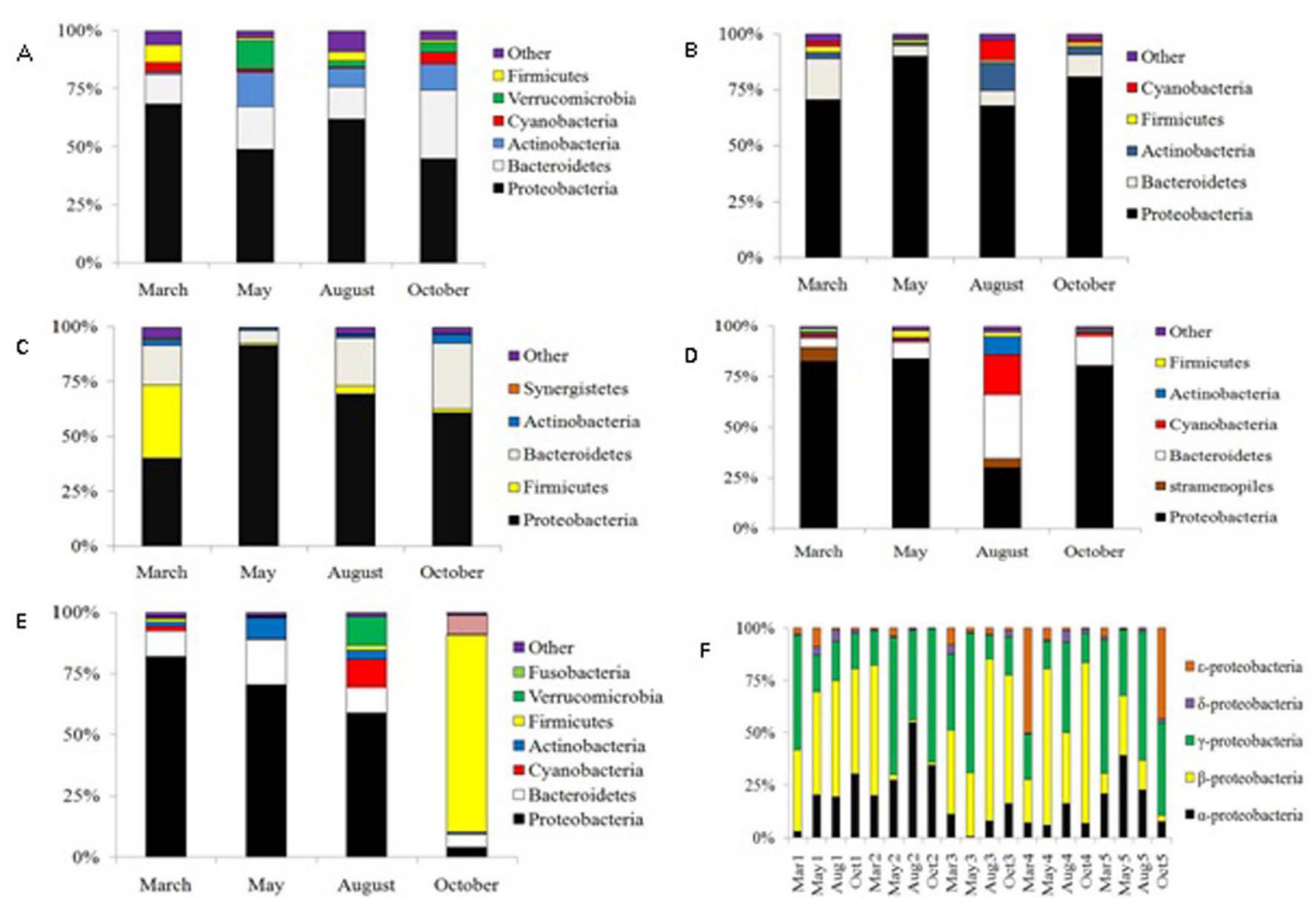

Figure 3. Relative abundance of phyla was analyzed in the five different wastewater systems analyzed in this study collected during different times of the year. A. sewage outfall S1; B. sewage outfall S2; C. sewage outfall S3; D. sewage outfall S4, and E. sewage outfall S5. F. Proteobacteria composition by class in the samples. After binning at the phylum level, bins that represented $<1 \%$ of the total sequences were labeled "other".

For S2, there was little difference among the samples collected over the course of the year (e.g., S2M3, S2M5, S2M8, and S2M10). As shown in Figure 3B, sequences affiliated with the Proteobacteria were dominant in all samples, followed by Actinobacteria, Bacteroidetes, and Firmicutes. In March, $\beta$-proteobacteria (62.3\% of total sequences) was the most abundant, while in other months $\gamma$-proteobacteria were the most abundant.

The composition of the bacterial community associated with sewage outfall S3 in March (Figure 3C) was dominated by Firmicutes (33\% of total sequences), which was higher than that found for the other 3 sampling times. Sequences affiliated with Proteobacteria in S3 sampled in March included $\alpha$-proteobacteria (11.1\% of total sequences), $\beta$-proteobacteria ( $40.2 \%$ of total sequences), $\gamma$-proteobacteria (36.1\% of total sequences), and $\varepsilon$-proteobacteria ( $8.1 \%$ of total sequences). However, in May, $\gamma$-proteobacteria was the most abundant $(67.0 \%$ 
of total sequences), with a slight decrease in the abundance of $\beta$-proteobacteria $(30.2 \%$ of total sequences). In August, the percentage of $\beta$-proteobacteria increased to $77.2 \%$ of total sequences, with the $\gamma$-proteobacteria representing only $11.4 \%$ of the total. In October, however, the percentage of $\alpha$-proteobacteria was nearly twice as high as that in August.

The composition of bacterial assemblages associated with sewage outfall S4 also shifted during the year (Figure 3D). The percentage of sequences affiliated with Proteobacteria was always greater $80 \%$ at three of the sampling points $(82.7 \%$ in March; $83.7 \%$ in May; $80.0 \%$ in October). However, in August, the percentage of sequences affiliated with the Proteobacteria was only $30.0 \%$, while the percentage of Bacteroidetes increased to $31.5 \%$. In March, $\varepsilon$-proteobacteria was the dominant group of Proteobacteria, where as for the other three months, the percentages were lower than $6 \%$. In May and October, the percentages of $\beta$-proteobacteria were 74.4 and $76.6 \%$, respectively.

According to a statistical analysis performed by the Ningbo City Ocean and Fishery Bureau, poor water quality was observed near the sewage outfall S5, which was the major drainage outfall. Proteobacteria was the dominant phylum in March, May, and August (Figure $3 \mathrm{E}$ ). However, during October, Proteobacteria comprised only $3.8 \%$ of the total bacterial population, while Firmicutes was the dominant phylum. $\delta$-Proteobacteria was the most rare group during the fourth month, making up less than $2 \%$ of the total population. During March, May, and August, $\varepsilon$-proteobacteria comprised 4.4, 0.5, and $0.4 \%$ of the total sample, respectively, but during October, it comprised $43.5 \%$ of the total. The change in the $\alpha$-proteobacteria population was also very clear, dropping from $21.0,39.1$, and $22.5 \%$ to $7.5 \%$ during the fourmonth period. For $\beta$-proteobacteria, the proportion was $28.6 \%$ in May, but during October, it was only $3.1 \%$. Although $\gamma$-proteobacteria was the dominant group during March, August, and October, its percentage differed cross these three months. During March and August, it comprised over $60 \%$ of the total population, but during October, it comprised only $44.0 \%$.

Significant variation in the composition and structure of microbial assemblages sampled across the 5-site seasonal gradient were detected. Although findings related to Proteobacteria were consistent with the results of other examinations, such as studies of activated sludge samples and wastewater treatment plants (Wong et al., 2005; Hu et al., 2012), Proteobacteria was the predominant phylum in Mar1, Mar2, Mar4, Mar5, May1, May2, May3, May4, May5, Aug1, Aug2, Aug3, Aug5, Oct2, Oct3, and Oct4, while in Mar3 and Oct5, Firmicutes was dominant, and in Aug4, Bacteroidetes was dominant; variation in the relative abundances of individual classes of Proteobacteria were evident across the 5 sites. $\alpha$-Proteobacteria, $\beta$-Proteobacteria, and $\gamma$-Proteobacteria represented $90 \%$ or more of all Proteobacteria (Figure 3F). This may have occurred because members of this phylum may originate from either wastewater or soil. The dominance of $\gamma$-Proteobacteria in the sewage wastefalls identified in this study included Enterobacteriaceae, Vibrionaceae, Pseudomonadaceae, Salmonella, Yersinia, Vibrio, and Pseudomonas aeruginosa, many of which are common in wastewaters and soils (Kent et al., 2001; Li et al., 2006; Schnetzer et al., 2011). This suggests that wastewater from sewage outfalls contains pathogenic bacteria. Through further sequence analysis, sequences belonging to pathogenic bacteria and degrading bacteria were detected. Many sequences from pathogenic bacteria were found. Further studies will be carried out on these pathogenic bacteria.

Moreover, the present characterization of wastewater from all 5 sewage out falls indicated the presence of pathogenic bacteria. $\alpha$-Proteobacteria is the dominant Proteobacterial 
class in the marine microbial community found at the surface of the Yellow Sea (Bai et al., 2009). In contrast, $\alpha$-Proteobacteria accounted for approximately $10 \%$ of all Proteobacteria found in the present study. $\beta$-Proteobacteria, which are uncommon in seawater samples (Sogin et al., 2006; Bai et al., 2009), accounted for approximately $30 \%$ of all Proteobacteria identified in our study.

The predominance of sequences affiliated with this phylum is likely attributable to environmental factors, such as $\mathrm{pH}$, phosphate levels, and Chemical Oxygen Demand (COD) (Casanovas-Massana and Blanch, 2012). The composition of the bacterial community associated with Oct5 differed from that of other samples. The predominant phylum in Oct5 was Firmicutes, which is ubiquitous in the environment (Stach et al., 2003; Urich et al., 2008). Many Firmicutes can produce endospores, which can resist dehydration and extreme environmental conditions (Li et al., 2011; Hu et al., 2012). Firmicutes are anaerobes, and this class may have become predominant because the system became anoxic. According to a statistical analysis performed by the Ningbo City Ocean and Fishery Bureau, there was considerable pollution and extreme environmental conditions at S5 in October, which likely account for the differences observed between sample Oct5 and the other samples.

The structures of the microbial communities in wastewater systems can be influenced by many factors, including salt concentration, geographical location, season, and rain, among others (Jiao et al., 2010; Jakobsson et al., 2010; Wang et al., 2011). In this study, we found that the $\alpha$-diversity index $\left(H^{\prime}, D, J\right)$, in which higher numbers represent more diversity, changed over the seasonal cycle. The results showed that in different seasons, the microbial diversity of sewage outfalls had a different geographic distribution: microbial diversity decreased from the inside port to the outside port. The microbial diversity in sample S5 was lower than in the other four samples, but diversity near the inside port was somewhat high. This maybe due to its location, where organic pollutants are greatly diluted. According to research performed by the Ningbo City Ocean and Fishery Bureau of China, the environment conditions were poor and the content of various organic pollutants and ammonia nitrogen materials exceeded our criteria, and this site was classified as a heavily polluted outlet (Ningbo City Ocean and Fishery Bureau). In general, diversity was found to be relatively high. The distribution of microbial diversity also differed over time. Overall, the bacterial diversity based on qualitative bacterial species and the quantities of the five sewage outfalls differed over time and space, revealing a close relationship with the classification of the sewage (Ningbo City Ocean and Fishery Bureau, China).

\section{CONCLUSION}

454-Pyrosequencing technology was used to investigate the composition of microbial communities associated with municipal wastewater in different seasons sampled over the course of one year. In the 20 samples, the taxonomic composition of the assemblages varied considerably, and the predominant phylum was Proteobacteria, followed by Bacteroidetes and Firmicutes. $\alpha$-Proteobacteria, $\beta$-proteobacteria, and $\gamma$-proteobacteria represented $90 \%$ or more of all Proteobacteria. In addition, variation in the classes of Proteobacteria was evident. These results suggest that the composition of microbial communities shift in response to seasonal and spatial gradients, which likely reflects variation in the physical and chemical characteristics of the sewage. 


\section{ACKNOWLEDGMENTS}

Research supported by State Oceanic Administration of China (\#201105007), by Ningbo Science Bureau of China (\#2008C50027), by K.C. Wong Magna Fund at Ningbo University, National Natural Science Foundation of China (\#31190109) and by The Outstanding (Postgraduate) Dissertation Growth Fundation of Ningbo University (\#PY2012002).

\section{REFERENCES}

Acosta-Martínez V, Dowd S, Sun Y and Allend V (2008). Tag-encoded pyrosequencing analysis of bacterial diversity in a singlesoil type as affected by management and land use. Soil Biol. Biochem. 40: 2762-2770.

Bai J, Li H and Zhao Y (2009). Bacterial distribution at different stations in the Northern Yellow Sea. Wei Sheng Wu Xue Bao 49: 343-350.

Bissett A, Richardson AE, Baker G and Thralla PH (2011). Long-term land use effects on soil microbial community structure and function. Appl. Soil Ecol. 51: 66-78.

Casanovas-Massana A and Blanch AR (2012). Diversity of the heterotrophic microbial populations for distinguishing natural mineral waters. Int. J. Food Microbiol. 153: 38-44.

Claesson MJ, O'Sullivan O, Wang Q, Nikkilä J, et al. (2009). Comparative analysis of pyrosequencing and a phylogenetic microarray for exploring microbial community structures in the human distal intestine. PloS One 4: e6669.

Cole JR, Wang Q, Cardenas E, Fish J, et al. (2009). The Ribosomal Database Project: improved alignments and new tools for rRNA analysis. Nucleic Acids Res. 37: D141-D145.

Cristea-Fernstrom M, Olofsson M, Chryssanthou E, Jonasson J, et al. (2007). Pyrosequencing of a short hypervariable 16S rDNA fragment for the identification of non tuberculous mycobacteria-a comparison with conventional 16S rDNA sequencing and phenotyping. APMIS 115: 1252-1259.

Despland LM, Vancov T, Aragno M and Clark MW (2012). Diversity of microbial communities in an attached-growth system using Bauxsol pellets for wastewater treatment. Sci. Total Environ. 433: 383-389.

Dethlefsen L, Huse S, Sogin ML and Relman DA (2008). The pervasive effects of an antibiotic on the human gut microbiota, as revealed by deep 16S rRNA sequencing. PLoS Biol. 6: e280.

Fabrice A and Didier R (2009). Exploring microbial diversity using 16SrRNA high-throughput methods. J. Comput. Sci. Syst. Biol. 2: 74-92.

Hu M, Wang X, Wen X and Xia Y (2012). Microbial community structures in different wastewater treatment plants as revealed by 454-pyrosequencing analysis. Bioresour. Technol. 117: 72-79.

Huber JA, Mark Welch DB, Morrison HG, Huse SM, et al. (2007). Microbial population structures in the deep marine biosphere. Science 318: 97-100.

Huse SM, Huber JA, Morrison HG, Sogin ML, et al. (2007). Accuracy and quality of massively parallel DNA pyrosequencing. Genome Biol. 8: R143.

Im WT, Kim DH, Kim KH and Kimb MS (2012). Bacterial community analyses by pyrosequencing in dark fermentative H2-producing reactor using organic wastes as a feedstock. Int. J. Hydrogen Energ. 37: 8330-8337.

Jakobsson HE, Jernberg C, Andersson AF, Sjolund-Karlsson M, et al. (2010). Short-term antibiotic treatment has differing long-term impacts on the human throat and gut microbiome. PLoS One 5: e9836.

Jiao YY, Li J, Guan WJ, Jiang SF, et al. (2010). Investigation of heave metals pollution in seawater and soils around a coastal industrial area. J. Environ. Occup. Med. 27: 645-649.

Kent KCB, David MK and Sallie WC (2001). Nutrient gradients in the western North Atlantic Ocean: relationship to microbial community structure and comparison to patterns in the Pacific Ocean. Deep Sea Res. 48: 2373-2395.

Li ZY, He LM, Wu J and Qun J (2006). Bacterial community diversity associated with four marine sponges from the South China Sea based on 16S rDNA-DGGE fingerprinting. J. Exp. Mar. Biol. Ecol. 329: 75-95.

Li J, Wang Z, Qin S and Wang G (2011). Microbial diversity of sediments from the coasts of Dalian Changshan Islands. Wei Sheng Wu Xue Bao 51: 656-666.

Liu Z, Lozupone C, Hamady M, Bushman FD, et al. (2007). Short pyrosequencing reads suffice for accurate microbial community analysis. Nucleic Acids Res. 35: e120.

Margulies M, Egholm M, Altman WE, Attiya S, et al. (2005). Genome sequencing in microfabricated high-density picolitre reactors. Nature 437: 376-380.

McKenna P, Hoffmann C, Minkah N, Aye PP, et al. (2008). The macaque gut microbiome in health, lentiviral infection, 
and chronic enterocolitis. PLoS Pathog. 4: e20.

McLellan SL, Huse SM, Mueller-Spitz SR, Andreishcheva EN, et al. (2010). Diversity and population structure of sewagederived microorganisms in wastewater treatment plant influent. Environ. Microbiol. 12: 378-392.

Nocker A, Burr M and Camper AK (2007). Genotypic microbial community profiling: a critical technical review. Microb. Ecol. 54: 276-289.

Qian PY, Wang Y, Lee OO, Lau SC, et al. (2011). Vertical stratification of microbial communities in the Red Sea revealed by $16 \mathrm{~S}$ rDNA pyrosequencing. ISME J. 5: 507-518.

Roesch LF, Fulthorpe RR, Riva A, Casella G, et al. (2007). Pyrosequencing enumerates and contrasts soil microbial diversity. ISME J. 1: 283-290.

Schnetzer A, Moorthi SD, Countway PD, Gastet RJ, et al. (2011). Depth matters: Microbial eukaryote diversity and community structure in the eastern North Pacific revealed through environmental gene libraries. Deep Sea Research Part I 58: 16-26.

Sogin ML, Morrison HG, Huber JA, Mark WD, et al. (2006). Microbial diversity in the deep sea and the underexplored "rare biosphere". Proc. Natl. Acad. Sci. U. S. A. 103: 12115-12120.

Stach JE, Maldonado LA, Masson DG, Ward AC, et al. (2003). Statistical approaches for estimating actinobacterial diversity in marine sediments. Appl. Environ. Microbiol. 69: 6189-6200.

Suau A, Bonnet R, Sutren M, Godon JJ, et al. (1999). Direct analysis of genes encoding 16S rRNA from complex communities reveals many novel molecular species within the human gut. Appl. Environ. Microbiol. 65: 4799-4807.

Sundquist A, Bigdeli S, Jalili R, Druzin ML, et al. (2007). Bacterial flora-typing with targeted, chip-based Pyrosequencing. BMC Microbiol. 7: 108.

Teodoro AC, Duleba W, Gubitoso S, Prada SM, et al. (2010). Analysis of foraminifera assemblages and sediment geochemical properties to characterise the environment near Araçá and Saco da Capela domestic sewage submarine outfalls of São Sebastião Channel, São Paulo State, Brazil. Mar. Pollut. Bull. 60: 536-553.

Urich T, Lanzén A, Qi J, Huson DH, et al. (2008). Simultaneous assessment of soil microbial community structure and function through analysis of the meta-transcriptome. PLoS One 3: e2527.

Wang Q, Garrity GM, Tiedje JM and Cole JR (2007). Naive Bayesian classifier for rapid assignment of rRNA sequences into the new bacterial taxonomy. Appl. Environ. Microbiol. 73: 5261-5267.

Wang ZH, Li TW, Su XR and Qin S (2011). Microbialcommunity diversity of the crudeoil and analysis of a strain DYL-1. Biotechnol. B 2: 163-168.

Wong MT, Mino T, Seviour RJ, Onuki M, et al. (2005). In situ identification and characterization of the microbial community structure of full-scale enhanced biological phosphorous removal plants in Japan. Water Res. 39: 2901-2914.

Ye L, Shao MF, Zhang T, Tong AH, et al. (2011). Analysis of the bacterial community in a laboratory-scale nitrification reactor and a wastewater treatment plant by 454-pyrosequencing. Water Res. 45: 4390-4398.

Yu J, Seon J, Park Y, Cho S, et al. (2012). Electricity generation and microbial community in a submerged-exchangeable microbial fuel cell system for low-strength domestic wastewater treatment. Bioresour. Technol. 117: 172-179. 